\title{
IL-4 induces cathepsin protease activity in tumor-associated macrophages to promote cancer growth and invasion
}

\author{
Vasilena Gocheva, ${ }^{1}$ Hao-Wei Wang, ${ }^{1}$ Bedrick B. Gadea, Tanaya Shree, Karen E. Hunter, \\ Alfred L. Garfall, Tara Berman, and Johanna A. Joyce ${ }^{2}$ \\ Cancer Biology and Genetics Program, Memorial Sloan-Kettering Cancer Center, New York, New York 10021, USA
}

\begin{abstract}
Innate immune cells can constitute a substantial proportion of the cells within the tumor microenvironment and have been associated with tumor malignancy in patients and animal models of cancer; however, the mechanisms by which they modulate cancer progression are incompletely understood. Here, we show that high levels of cathepsin protease activity are induced in the majority of macrophages in the microenvironment of pancreatic islet cancers, mammary tumors, and lung metastases during malignant progression. We further show that tumor-associated macrophage (TAM)-supplied cathepsins $B$ and $S$ are critical for promoting pancreatic tumor growth, angiogenesis, and invasion in vivo, and markedly enhance the invasiveness of cancer cells in culture. Finally, we demonstrate that interleukin-4 (IL-4) is responsible for inducing cathepsin activity in macrophages in vitro and in vivo. Together, these data establish IL-4 as an important regulator, and cathepsin proteases as critical mediators, of the cancer-promoting functions of TAMs.
\end{abstract}

[Keywords: Tumor-associated macrophage; tumor microenvironment; cysteine cathepsin; protease; interleukin-4; invasion]

Supplemental material is available at http://www.genesdev.org.

Received October 13, 2009; revised version accepted December 3, 2009.

Cancers develop in a complex tissue microenvironment, comprising innate and adaptive immune cells, fibroblasts, the blood and lymphatic vascular networks, and the extracellular matrix (ECM), which collectively have critical modulatory functions in tumor development (Tlsty and Coussens 2006; Joyce and Pollard 2009). An inflammatory cell infiltrate is an important component of the tumor microenvironment, and many clinical studies have established a positive correlation between inflammation and cancer progression (Mantovani et al. 2008). This is not unexpected, as stromal cells that infiltrate the tumor mass can secrete a variety of tumor-promoting factors including growth factors, chemokines, and proteases (Murdoch et al. 2008). Because the physiological roles of many innate immune cells require production of proteases, it is plausible that some of their proteolytic capabilities are usurped during cancer progression. Proteases have been studied in cancer for many years, with a major focus on matrix metalloproteases; recently, however, critical roles have been reported for other protease families, including the cysteine cathepsins.

\footnotetext{
${ }^{1}$ These authors contributed equally to this work.

${ }^{2}$ Corresponding author.

E-MAIL joycej@mskcc.org; FAX (646) 422-0231.

Article published online ahead of print. Article and publication date are online at http://www.genesdev.org/cgi/doi/10.1101/gad.1874010.
}

There are 11 human cysteine cathepsin proteases (Cts) (B, C, H, F, K, L, O, S, V, W, and X/Z) that share a conserved active site formed by cysteine and histidine residues (Vasiljeva et al. 2007). Cathepsins not only mediate terminal protein degradation in the lysosomes, they also process and activate proteins including growth factors, transcription factors, and other proteases (Vasiljeva et al. 2007). Members of the cathepsin family have been implicated in the progression of human cancers, based on their increased expression, elevated activity, and altered localization from the lysosomes to the cell surface in many tumor types, which are usually associated with poor prognosis (Mohamed and Sloane 2006).

Interestingly, clinical studies in various tumor types have shown that certain cathepsins-including Cts B, L, and S-are supplied to the tumor by stromal cells (Iacobuzio-Donahue et al. 1997; Hazen et al. 2000; Lindahl et al. 2009; Sullivan et al. 2009), although the significance of these observations remains unknown. From a therapeutic perspective, it is critical to understand the complex interplay between different cell types in the tumor microenvironment, to develop approaches that either selectively target these cells or block the communication between them. In this study, we thus set out to determine the relative functional contributions of tumorderived versus stromal-derived cathepsin proteases to 
tumor progression, and to identify the factors that upregulate cathepsins in the tumor microenvironment.

Here we identify tumor-associated macrophages (TAMs) as the primary source of high levels of cathepsin activity in pancreatic islet cancers, mammary tumors, and lung metastases. We show that the production of Cts $\mathrm{B}$ and $\mathrm{S}$ by TAMs is critical for promoting pancreatic tumor growth, angiogenesis, and invasion in vivo. Moreover, macrophage-supplied Cts B and S markedly enhance the invasiveness of cancer cells in culture. Finally, we identify interleukin-4 (IL-4) as a key factor responsible for inducing cathepsin activity in macrophages in vitro and in vivo. Collectively, these data establish IL-4 as an important regulator, and cathepsin proteases as critical mediators, of the cancer-promoting functions of TAMs.

\section{Results}

Cathepsin activity in TAMs increases during pancreatic islet cancer and mammary cancer development

In order to investigate the roles of stromal cathepsins in tumorigenesis, we first analyzed the RIP1-Tag2 (RT2) mouse model of pancreatic islet cell cancer, which progresses through sequential stages including hyperplastic islets, angiogenic islets, and various grades of carcinoma (Hanahan 1985). This is a particularly suitable model for the present study, as we showed previously through pharmacological and genetic analyses that certain cathepsin family members-including Cts B, L, and $\mathrm{S}$-are important for tumor growth and development (Joyce et al. 2004; Gocheva et al. 2006). Moreover, we found that several of the key cathepsins implicated in RT2 tumorigenesis are also expressed in human pancreatic islet tumors, and their increased expression correlates with malignant progression in human patients (Gocheva et al. 2006), thus validating the utility of this model.

Interestingly, we made the initial observation through quantitative RT-PCR analysis of FACS-purified constituent cells from RT2 lesions that several of the cathepsins were highly enriched or exclusively expressed in infiltrating innate immune cells, while Cts $\mathrm{L}$, and, to a lesser degree Cts B, were expressed in the tumor cells (Joyce et al. 2004). Unlike many other classes of proteins, the activity of proteolytic enzymes is highly and predominately regulated at post-translational stages, with cathepsins requiring proteolytic cleavage of a propeptide sequence for activation. Thus it is critical to directly assay enzymatic activity rather than inferring it from mRNA or protein expression data.

As such, we used a cathepsin activity-based probe (ABP) that binds covalently and irreversibly in the catalytic site of active cysteine cathepsins, providing a direct and quantitative readout of enzymatic activity (Greenbaum et al. 2002), in order to identify the individual cell types producing active cathepsin enzymes in vivo. The specificity of the ABP for the cathepsin family was demonstrated previously by competitive blocking of the ABP signal in vivo and ex vivo via pretreatment with a pan- cathepsin inhibitor, JPM-OEt (Joyce et al. 2004). Here, we synthesized a modified cathepsin ABP in which we conjugated $\mathrm{Cy} 3 \mathrm{~B}$, a brighter fluorophore with a tighter emission spectrum than the BODIPY fluorophore used previously, to the original epoxide scaffold (abbreviated as Cath-ABP) (Fig. 1A), which then enabled colabeling with cell-type-specific markers. The Cath-ABP was injected into RT2 mice at each stage of tumor development, allowing us to visualize cathepsin activity in vivo and identify infiltrating macrophages $\left(\mathrm{F} 4 / 80^{+}\right)$as the major source of high levels of active cathepsins in the tumor microenvironment (Fig. 1B). Costaining with additional macrophage markers CD68 and Ibal confirmed this finding (Supplemental Fig. S1A). Quantitative image analysis revealed that $93.4 \%$ of the cells with high cathepsin activity (Cath- $\mathrm{ABP}^{+}$) were $\mathrm{CD} 45^{+}$cells, mostly F4/80 $0^{+}$macrophages (92.5\%) (Fig. 1C; Supplemental Fig. $\mathrm{S} 1 \mathrm{~A}, \mathrm{~B})$. The remaining Cath- $\mathrm{ABP}^{+}$cells in RT2 tumors that were $\mathrm{F} 4 / 80^{-}$included occasional $\mathrm{CD}^{+} \mathrm{T}$ cells, $\mathrm{CD} 1^{+}$endothelial cells, and $\mathrm{FSP}^{+}$fibroblasts (Supplemental Fig. S1A; data not shown). Immunostaining for other stromal cells in the tumor microenvironment, including neutrophils $\left(7 / 4^{+}\right.$and $\left.\mathrm{Gr}-1^{+}\right)$and pericytes $\left(\mathrm{NG}^{+}\right.$and $\left.\mathrm{PDGFR}^{+}\right)$, did not reveal any colocalization with the cathepsin activity signal (data not shown).

We additionally examined protein expression using antibodies specific for each cathepsin family member and found that Cts B, C, and S are highly expressed in CD $45^{+}$leukocytes (Supplemental Fig. S2A). In contrast, Cts $\mathrm{L}$ is expressed in some CD $45^{+}$cells, but the majority of its expression is tumor cell-derived (Supplemental Fig. $\mathrm{S} 2 \mathrm{~A}, \mathrm{~B})$. Cts B protein can be detected in tumor cells, albeit at much lower levels than Cts L, consistent with our previous mRNA expression data from flow cytometrysorted cells (Joyce et al. 2004). Furthermore, we found that Cts B, C, and S are highly expressed in all TAMs, with a smaller proportion of TAMs expressing Cts $\mathrm{L}$ (Supplemental Fig. S2C).

Interestingly, while $\mathrm{F} 4 / 80^{+}$cells were clearly present in normal and hyperplastic islets in the early stages of RT2 tumorigenesis, they produced little or no cathepsin activity detectable by the Cath-ABP (Fig. 1B). However, concomitant with the induction of new blood vessel formation, termed angiogenic switching, abundant cathepsin activity was visualized in macrophages infiltrating the preneoplastic lesions. In end-stage tumors, cathepsin activity was enriched in macrophages located adjacent to blood vessels (Supplemental Fig. S1C) and at the invasive tumor front (Fig. 1B). Furthermore, there was a striking difference in cathepsin activity levels in TAMs compared with macrophages in the adjacent normal pancreas (Fig. 1D).

To investigate the broader relevance of this finding, we imaged cathepsin activity in the MMTV-PyMT (PyMT) mouse model of mammary tumorigenesis. These mice successively develop hyperplastic, angiogenic, and invasive lesions in the mammary glands, and lung metastases with almost complete penetrance (Guy et al. 1992; Lin et al. 2003). Cath-ABP ${ }^{+}$cells are found in greater abundance in advanced primary and metastatic lesions 
A

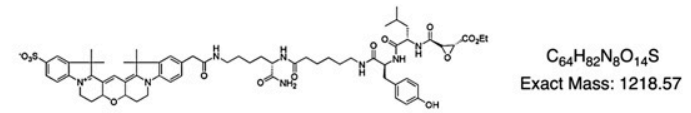

B

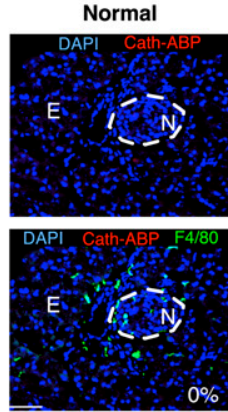

Hyperplastic (8wks)
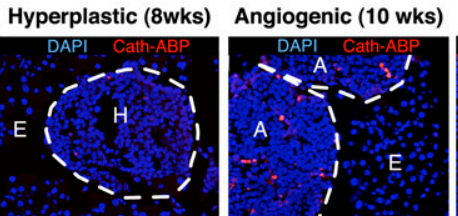

Tumor (13.5 wks)

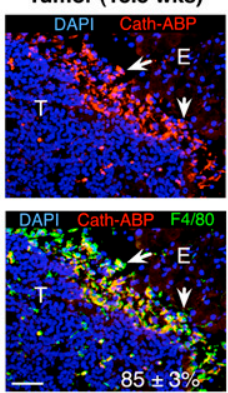

C

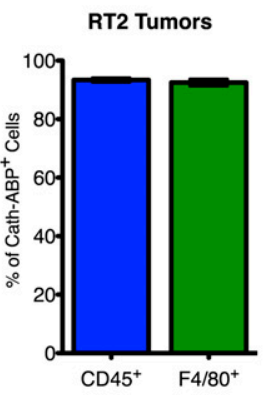

D

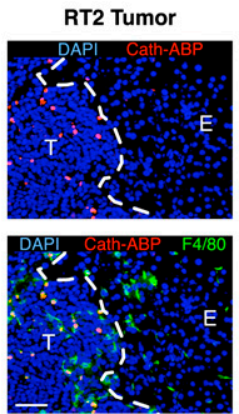

E

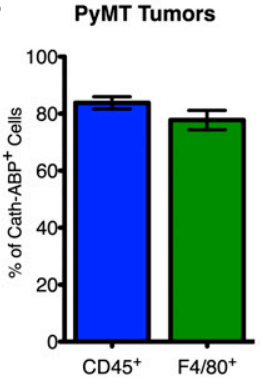

$\mathbf{F}$
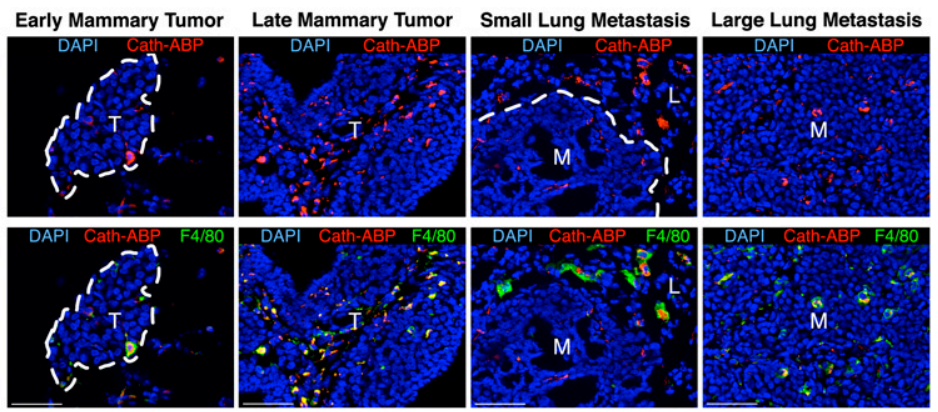

Figure 1. Increase in cathepsin activity in TAMs during pancreatic islet and mammary cancer development. (A) Chemical structure of Cath-ABP. (B) Cathepsins are highly activated in infiltrating macrophages during tumor progression at the angiogenic islet and tumor stages of RT2 tumorigenesis. Pancreatic tissue from mice injected with the Cath-ABP was stained with an $\alpha-F 4 / 80$ antibody. Groups of four or more mice were analyzed per stage and three or more lesions per mouse. Normal (N) $\mathrm{Tag}^{+}$islets were analyzed at 4-7 wk, hyperplastic $(\mathrm{H})$ islets at $8 \mathrm{wk}$, angiogenic (A) islets at $10 \mathrm{wk}$, and tumors (T) at 13.5 wk of age. The percentage of $\mathrm{F} 4 / 80^{+}$cells that were Cath- $\mathrm{ABP}^{+}$was determined by image analysis and is indicated in the image for each stage. Macrophages present in the normal exocrine (E) pancreas were omitted from the analysis. Arrows represent the invasive tumor front. $(C)$ Graph showing the percent of Cath- $\mathrm{ABP}^{+}$cells in RT2 tumors that colocalize with $\mathrm{F} 4 / 80$ or CD45, as determined by image analysis using TissueGnostics software ( $n=18$ tumors). Data are represented as the mean \pm SEM. $(D)$ Representative image of a tumor $(\mathrm{T})$ from a 13.5-wk-old RT2 mouse showing macrophages inside the lesion with high levels of cathepsin activity as compared with those in the adjacent normal exocrine (E) pancreas. $(E)$ Graph showing the percent of Cath- $\mathrm{ABP}^{+}$cells in PyMT tumors that colocalize with CD45 $(n=10$ tumors from four independent mice) or F4/80 ( $n=9$ tumors from four independent mice), analyzed as in $C$. $(F)$ Cathepsins are highly activated in TAMs during mammary tumor $(\mathrm{T})$ development and lung metastasis $(\mathrm{M})$ in PyMT mice. Early mammary tumors were obtained from 9-wk-old mice, late tumors were obtained from 14-wk-old mice, and small and large lung metastases were obtained from 14-wk old mice, which have variable lung metastatic burdens. The adjacent normal lung (L) parenchyma is shown for comparison. Bars, $50 \mu \mathrm{m}$.

compared with earlier ones (Fig. 1F). Again, TAMs are the major supplier of high levels of active cathepsins in both cases (Fig. 1F). Quantification of Cath-ABP ${ }^{+}$cells by image analysis in mammary tumors showed that $84 \%$ were $\mathrm{CD}_{4} 5^{+}$and $78 \%$ were F4/80 $($ Fig. 1E; Supplemental Fig. S1D). The remaining Cath- $\mathrm{ABP}^{+}$cells that are $\mathrm{CD} 45^{-}$ include a subset of tumor cells identified by costaining with epithelial cell adhesion molecule EpCAM (Supplemental Fig. S1E), and occasional apoptotic cells (data not shown).

To confirm the in vivo labeling of cathepsin activity, single-cell suspensions prepared from whole RT2 tumors (from 13.5-wk-old mice) were labeled ex vivo with the Cath-ABP and analyzed by flow cytometry, which revealed three different cell populations: Cath-ABP ${ }^{\text {neg/low }}$, Cath-ABP ${ }^{\text {med }}$, and Cath-ABP ${ }^{\text {high }}$ (Fig. 2A). Colabeling with F4/80 demonstrated that the Cath-ABP ${ }^{\text {high }}$ population predominantly consists of TAMs, and that $77 \% \pm 5 \%$ of $\mathrm{F} 4 / 80^{+}$TAMs exhibit high levels of cathepsin activity (Fig. 2B). Importantly, the Cath-ABP ${ }^{\text {med }}$ popula- tion likely includes cancer cells that produce active cathepsins, although at much lower levels than TAMs, consistent with the lack of Cath-ABP signal observed from these cells by fluorescence microscopy, which is less sensitive than flow cytometry. Additionally, analysis of TAMs in PyMT tumors (from 14- to 16-wk-old mice) by flow cytometry revealed a similar proportion of $\mathrm{F} 4 / 80^{+}$ cells that are Cath-ABP high $(73 \% \pm 4 \%)$ (Fig. 2B). Thus, we determined that the numbers of Cath-ABP ${ }^{\text {high }}$ cells increase as neoplastic lesions develop in the pancreas and breast. While lower levels of active cathepsins are found in tumor cells, in both mouse models studied, TAMs are the major contributing source of high levels of cathepsin activity.

Increased cathepsin activation in macrophages occurs locally in the tumor microenvironment

The induction of cathepsin activity we observe in TAMs during cancer progression could be due to a local effect of 
A

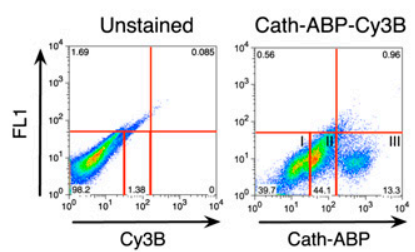

C

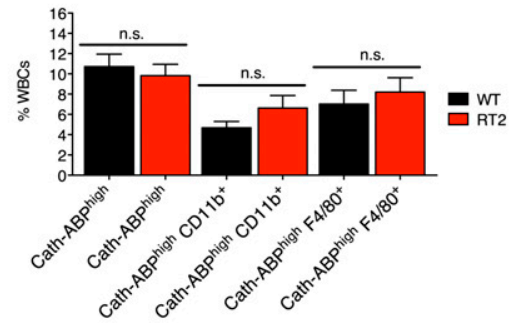

D

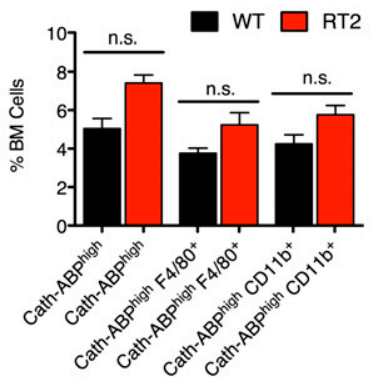

E

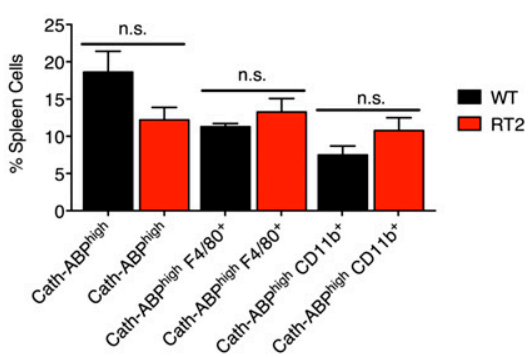

B
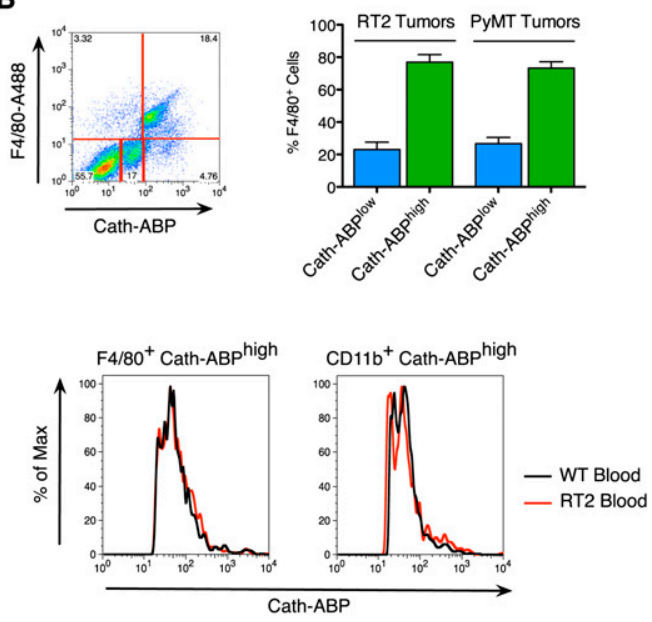

-WT Bone Marrow -RT2 Bone Marrow

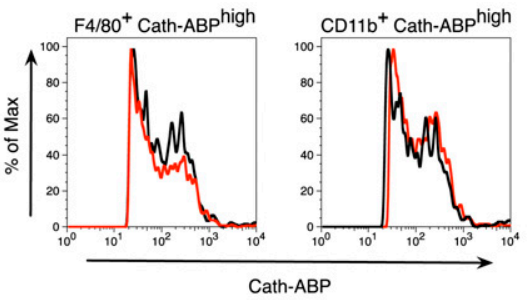

F
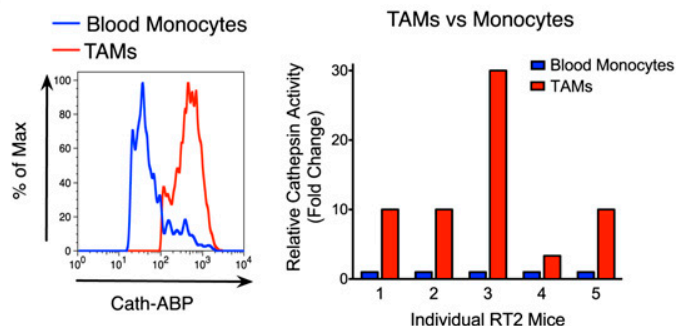

Figure 2. Macrophages infiltrating the local tumor microenvironment of pancreatic islet tumors have high levels of cathepsin activity. (A) Flow cytometry was used to label whole-tumor suspensions from RT2 mice ex vivo with the Cath-ABP. Subsequent analysis revealed three different levels of cathepsin activation in whole tumors: negative/low (I), medium (II), and high (III) ( $n=13 \mathrm{mice})$. (B) The majority of macrophages present inside RT2 and PyMT tumors have high levels of cathepsin activity. Whole-tumor suspensions were labeled with the Cath-ABP and $\alpha-\mathrm{F} 4 / 80$, and the proportion of macrophages with high and low levels of cathepsin activity was quantified by flow cytometry. A representative plot from a RT2 sample is shown on the left (RT2 mice, $n=7 ;$ PyMT mice, $n=9)$. (C) Cathepsin activity is not elevated in circulating monocytes from RT2 tumor-bearing mice compared with wild-type (WT) mice. WBCs isolated from wild-type and RT2 mice were labeled ex vivo with the Cath-ABP, $\alpha$-F4/80, and $\alpha$-CD11b antibodies. The number of Cath$\mathrm{ABP}^{\text {high }}$ cells in the blood (graph) and the level of activation (flow cytometry plots) were determined; (n.s.) not significant ( $n>5$ mice). (D) Cathepsin proteases are not significantly activated in the BM of RT2 mice when compared with wild-type littermates. BM cells from wild-type and RT2 mice were stained and analyzed as in $C$. $(E)$ Cathepsin proteases are not significantly activated in the spleen of RT2 mice when compared with wild-type littermates. Spleen cells from wild-type and RT2 mice were stained as in $C$. $(F)$ The level of cathepsin activity is enhanced in TAMs compared with blood monocytes of RT2 mice. Cathepsin activation was determined by labeling blood and tumor suspensions from individual RT2 mice with the Cath-ABP and $\alpha-\mathrm{F} 4 / 80$. The mean fluorescence intensity of cathepsin activity was determined for TAMs and blood monocytes from each mouse, and the relative cathepsin activity in TAMs versus blood monocytes is shown in the graph for five individual animals. Cathepsin activity was 12.7-fold higher on average in TAMs compared with monocytes; $P=0.028$.

the tumor on infiltrating macrophages or a systemic effect exerted by the tumor on macrophage precursors in the bone marrow (BM) or blood prior to their arrival at the tumor. To test this, cell suspensions from the BM, blood, spleen, and tumors of RT2 mice were labeled with the Cath-ABP in conjunction with cell-type-specific 
antibodies. Analysis by flow cytometry of total white blood cells (WBCs) from wild-type mice revealed that only $\sim 10 \%$ of cells exhibit high levels of cathepsin activity, and this proportion of Cath-ABP ${ }^{\text {high }}$ WBCs was not increased in RT2 tumor-bearing animals (Fig. 2C). Moreover, double-labeling of WBC suspensions with F4/ 80 or CD11b, a general myeloid cell marker, did not reveal any significant alterations in either the numbers of Cath-ABP ${ }^{\text {high }}$ monocytes or their levels of cathepsin activity in RT2 versus wild-type mice (Fig. 2C). Analysis of BM and spleen cells also indicated that cathepsin activity levels in these organs do not appear to be different in RT2 mice compared with wild-type mice (Fig. 2D,E). However, comparison of cathepsin activity levels in TAMs versus blood monocytes isolated from the same RT2 animal revealed a pronounced increase in cathepsin activity (12.7-fold \pm fivefold higher; $P=0.028$ ) among macrophages that had infiltrated the tumor compared with their circulating precursors (Fig. 2F). Therefore, we conclude that, in RT2 mice, increased cathepsin activity is an attribute of TAMs located within the tumor microenvironment rather than a systemic phenomenon.

\section{Depletion of macrophage-derived Cts B or S significantly impairs RT2 tumor progression}

The data above demonstrate that the majority of TAMs in the microenvironment of pancreatic islet cancers, mammary tumors, and lung metastases produce high levels of active cathepsins. To determine whether the induction of cathepsin activity we identified in TAMs actually contributes to tumorigenesis, we performed BM transplantation (BMT) experiments to remove individual Cts genes from hematopoietic cells and assessed the effects on pancreatic tumor development. RT2 recipients were lethally irradiated at 4 wk of age, a time point that was selected to precede the development of the earliest preneoplastic stage, before cathepsin activation is induced. Following transplant with Cts-deficient or wildtype $\mathrm{BM}$, recipient animals were aged to $13.5 \mathrm{wk}$ of age, the end-stage time point in RT2 mice (Fig. 3A).
A
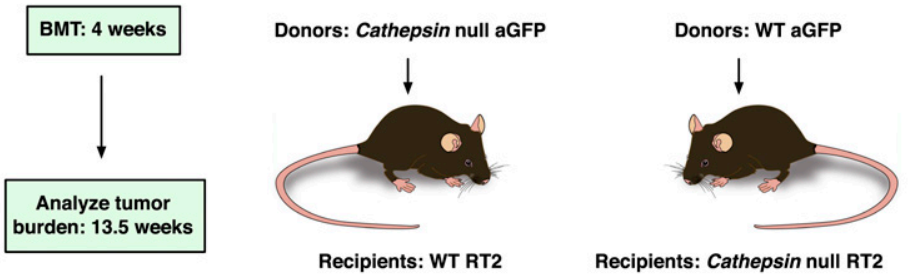

B
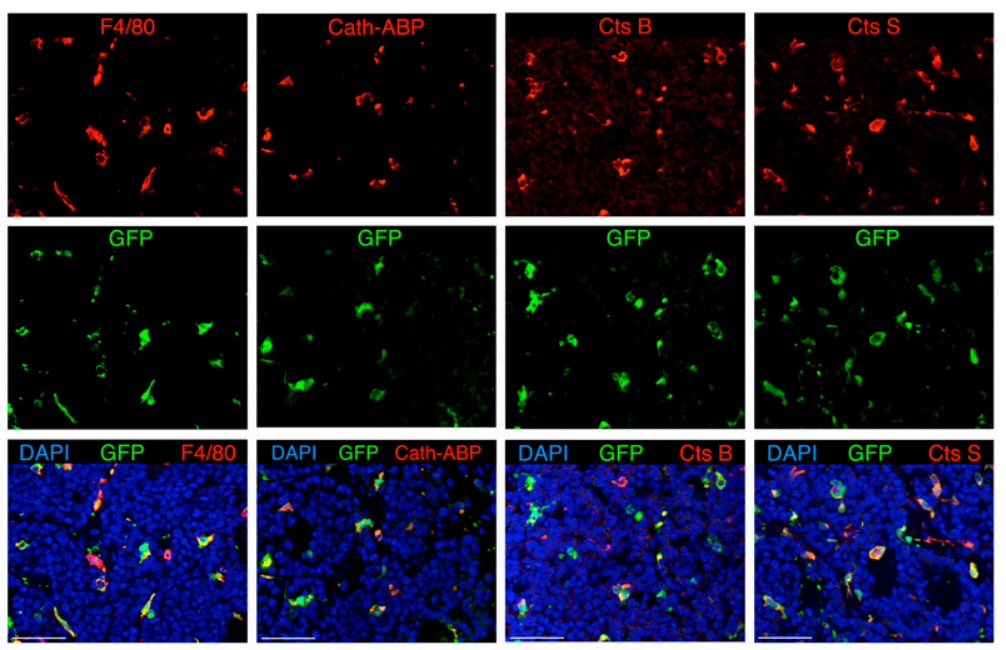

C

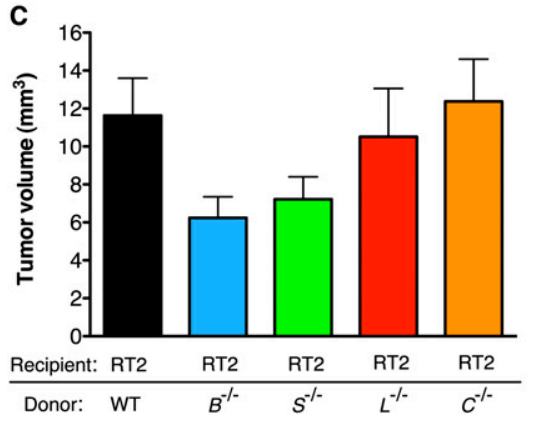

D

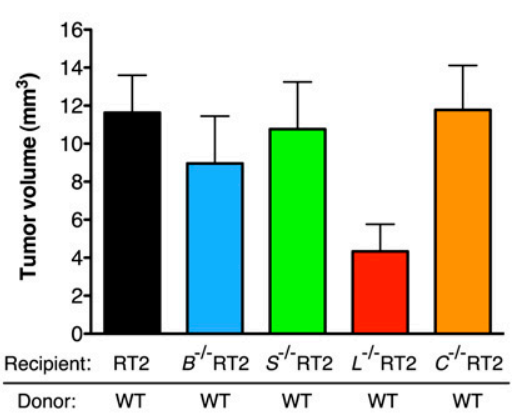

Figure 3. Removal of BM-derived Cts $B$ and $S$ significantly impairs RT2 tumor progression. (A) Schematic of the BMT experimental design. (B) The vast majority of BMDCs that infiltrate tumors of RT2 mice transplanted with $\mathrm{GFP}^{+}$wild-type (WT) BM differentiate into $\mathrm{F} 4 / 80^{+}$macrophages, which supply cathepsin activity and express Cts $\mathrm{B}$ and $\mathrm{S}$ as indicated by immunofluorescence analysis. Bar, $50 \mu \mathrm{m} .(C)$ Tumor burden was decreased in RT2 mice transplanted with $C t s B$ - or $S$-null BM. The total number of BMT recipient mice analyzed were as follows: wild type (WT), $24 ; B^{-1-}$, $20(P<0.05) ; S^{-/-}, 24 ; L^{-/-}, 15 ; C^{-/-}, 18 .(D)$ Supplying wild-type BM to individual $C$ ts $B$ or $S$-null, but not $L$-null, RT2 mice restored the tumor burden to wild-type RT2 levels. The following number of BMT recipient mice were analyzed: wild-type (WT) RT2, 24; $B^{-/-} \mathrm{RT} 2,12 ; S^{-/-} \mathrm{RT} 2,13 ; L^{-/-} \mathrm{RT} 2,3$; $C^{-/-} \mathrm{RT} 2,15$. 
We first wanted to establish that the BMT experiments would be an appropriate method to predominantly target macrophage-derived cathepsins, and thus determined which cell types constitute the BM-derived cell (BMDC) population within RT2 tumors. We transplanted actin$\mathrm{GFP}^{+}$wild-type BM into wild-type $\mathrm{RT} 2$ recipients, which revealed an abundant infiltration of $\mathrm{GFP}^{+}$BMDCs. Costaining with a panel of cell-type-specific markers showed that the BMDCs are $\mathrm{CD} 45^{+}$as expected (Supplemental Fig. S3A), and the majority are $\mathrm{F} 4 / 80^{+}$macrophages $(88 \% \pm$ $0.5 \%$ of $\mathrm{GFP}^{+}$cells, by image analysis) (Fig. 3B). This was confirmed by CD68 staining and by flow cytometry (Supplemental Fig. S3A; data not shown). Moreover, injection of the Cath-ABP showed that most BM-derived $\mathrm{GFP}^{+}$macrophages supply active cathepsins, and immunostaining showed that they express Cts B and S (Fig. 3B). Very few $\mathrm{GFP}^{+}$cells colabeled with markers specific for neutrophils or B cells, while there was no colocalization with markers for endothelial cells or pericytes (Supplemental Fig. S3A; data not shown). The majority of macrophages in the $\mathrm{BMT}$ recipient tumors were $\mathrm{GFP}^{+}$ $\left(83 \% \pm 1.6 \%\right.$ of $\mathrm{F} 4 / 80^{+}$cells, by image analysis), indicating efficient reconstitution by the donor BM.

Since the vast majority of TAMs in transplanted mice are donor BM-derived and produce active cathepsins, we inferred that removal of individual Cts genes from the BM would allow us to determine the contribution of these genes to TAM functions during tumorigenesis. We generated Cts $B^{-/-}, C^{-1-}, L^{-/-}, S^{-/-}$, or wild-type mice carrying an actin-GFP ${ }^{+}$transgene in order to track the donor cells in recipient animals. We transplanted BMDCs from each of these genotypes to lethally irradiated RT2 recipients. We first ensured that each individual Cts-null donor BM fully reconstituted the recipient animal by analyzing the peripheral blood and BM (Supplemental Fig. S4A,B). Deletion of any of the four Cts genes did not affect reconstitution in either site, indicating that removal of individual cathepsins does not interfere with the process of BM engraftment and hematopoiesis in the adult. Moreover, there were equivalent numbers of $\mathrm{GFP}^{+}$ BMDCs, leukocytes, TAMs, B cells, T cells, and neutrophils in tumors of RT2 mice that received Cts $B^{-/-}$or $S^{-/-}$ BM compared with wild-type BM (Supplemental Fig. S3B), indicating that removal of individual cathepsins did not affect the relative proportions of specific leukocyte populations, or their ability to home to and infiltrate the tumor mass.

A comparison of tumor burden at end stage revealed a substantial reduction in tumor volume in RT2 recipients that had received $C t s B^{-/-}$or $S^{-/-} \mathrm{BM}(46 \%, P<0.05$ and $38 \%$ decrease, respectively) (Fig. 3C). On the other hand, removal of Cts $L$ or $C$ from the BM had no effect on tumor growth (Fig. 3C). These data suggest that, while all four cathepsins are produced by TAMs, albeit to different extents, of these, Cts B and S are the only TAM-derived cathepsins that enhance tumor growth.

We next sought to determine whether restoring individual cathepsins to TAMs would be sufficient to rescue tumor development in an otherwise Cts-deficient animal, and performed the converse experiment, in which wild-type BM was transplanted into Cts-null RT2 mice (Fig. 3A). We showed previously that constitutive deletion of $C t s B, S$, or $L$ reduced tumor burden to varying degrees (Gocheva et al. 2006). In the present study, transplantation of wild-type BM restored the tumor burden of $C t s B^{-1-}$ RT2 and Cts $S^{-1-}$ RT2 mice to $77 \%$ and $93 \%$ of wild-type RT2, respectively (Fig. 3D). The partial restoration of tumor growth by supplying wildtype $\mathrm{BM}$ to $C$ ts $B^{-/-} \mathrm{RT} 2$ mice is consistent with our observation that, while Cts B protein is highly enriched in immune cells, it is also expressed at low levels in cancer cells (Supplemental Fig. S2B). On the contrary, transplantation of wild-type BM into Cts $L^{-/-}$RT2 mice did not restore tumor growth, indicating that the tumorpromoting functions of Cts $\mathrm{L}$ are provided by either cancer cells, or other cells that do not originate in the BM. We performed additional BMT control experiments in which $C$ ts $B^{-1-}$ or $S^{-1-}$ BM was transplanted into Cts $B^{-/-}$or $S^{-/-}$RT2 recipients, respectively (Supplemental Fig. S4C), which resulted in a similar relative reduction in tumor volume as observed previously in the constitutive knockouts (Gocheva et al. 2006). Taken together, these results show that TAMs abundantly supply active cathepsins to the tumor microenvironment, and that it is macrophage-derived Cts B and S that play important roles in promoting pancreatic tumor development.

\section{Removal of macrophage-derived Cts B or S impairs tumor invasion and angiogenesis}

Given our data above showing that macrophage-supplied Cts B and S play critical roles in enhancing tumor growth, and our finding that cathepsin-active TAMs accumulate along the invasive fronts of RT2 tumors (Fig. 1B), we wanted to determine whether the production of Cts B or S from TAMs contributes to pancreatic tumor invasion. Tumors in RT2 mice are graded for invasion into three classes: benign encapsulated tumors, microinvasive carcinomas, and frankly invasive carcinomas (Lopez and Hanahan 2002). The majority of tumors in wild-type RT2 mice that received wild-type BM were classified in the two invasive categories (Fig. 4A). This contrasts with wild-type RT2 mice receiving either Cts B- or S-null BM, which both showed a significant reduction in tumor invasion $(P<0.0001)$. In contrast, removal of either $C t s$ $C$ or $L$ from the BM did not have a significant effect on tumor invasion.

We also investigated whether the restoration of wildtype BM into otherwise Cts-null RT2 mice would affect invasion. We showed previously that constitutive deletion of $C$ ts $B, L$, or $S$ in RT2 mice significantly reduced tumor invasion (Gocheva et al. 2006). Transplantation of wild-type BM into each of the four Cts mutant RT2 lines had distinct effects on tumor invasiveness, restoring it to wild-type RT2 levels in both Cts $B^{-/-}$RT2 and Cts $S^{-/-}$ RT2 mice, but not affecting the reduced tumor invasion typically seen in Cts $L^{-1-}$ RT2 mice (Fig. 4B). Constitutive deletion of Cts $C$ in RT2 mice results in the same spectrum of tumor grades as wild-type RT2 animals (Gocheva et al. 2006), and this was not affected in either 

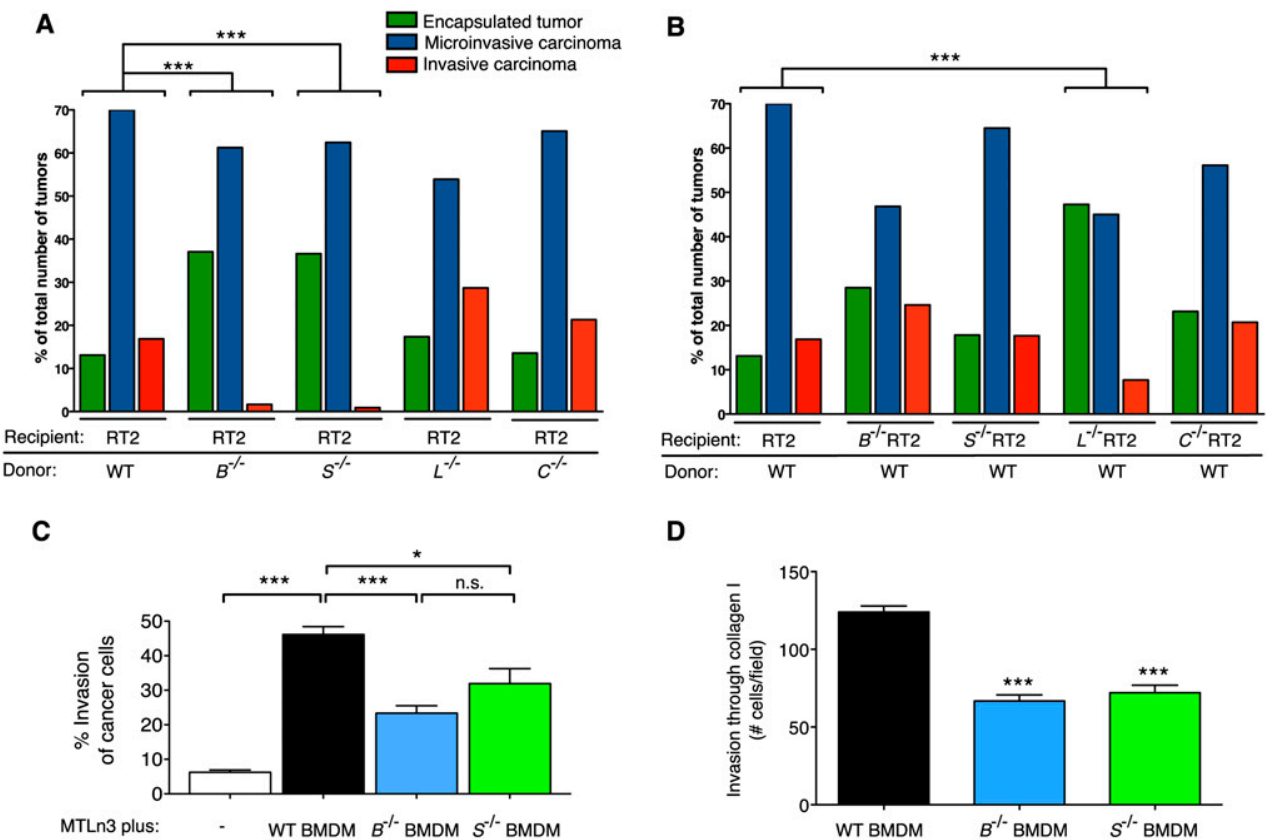

D

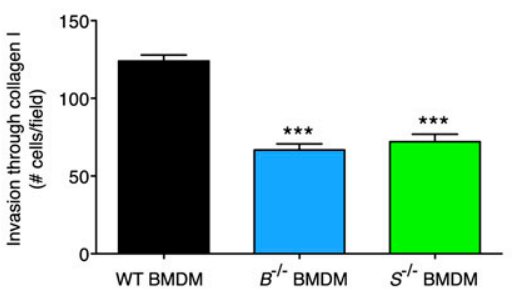

$\mathbf{E}$
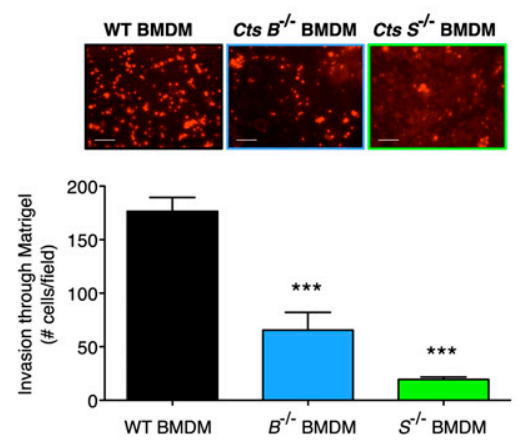

$\mathbf{F}$

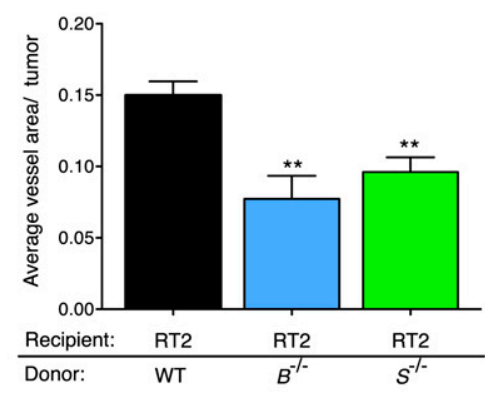

Figure 4. Removal of macrophage-derived Cts $B$ or $S$ impairs cancer cell invasion and angiogenesis. $(A) \mathrm{H} \& \mathrm{E}$ staining was used to grade tumors from BM-transplanted RT2 mice. Graph showing the relative proportions of encapsulated, microinvasive, and invasive carcinomas in RT2 mice that received wild-type (WT) BM compared with those that received Cts-null BM. Deletion of Cts B or $S$ in the BM resulted in a substantial decrease in tumor invasiveness $\left(\left[{ }^{\star \star}\right] P \leq 0.0001\right.$ compared with wild type), whereas removal of $C t s C$ or $L$ from the BM had no significant effect. $(B)$ Invasion grading and analysis was performed on Cts-null RT2 mice transplanted with wildtype BM. Transfer of wild-type BM into Cts $B$ - or $S$-null RT2 recipients restored tumor invasiveness to wild-type RT2 levels, but had no effect on the reduced tumor invasion observed in Cts $L$-null RT2 mice; $\left(^{\star \star \star}{ }^{\star}\right) P<0.0001$ compared with wild type. $(C)$ Removal of $C t s B$ or $S$ from macrophages reduced macrophage-induced invasion of breast cancer cell line MTLn3. The ability of BMDMs isolated from wild-type, $C t s B^{-1-}$ or $S^{-1-}$ mice to promote invasion of cancer cells into an overlying collagen I matrix was determined. Cancer cells invading $>15 \mu \mathrm{m}$ were scored as invasive in three independent experiments performed in triplicate; $\left(^{\star}\right) P<0.05 ;\left(^{\star \star \star}\right) P<^{*} 0.0001$ compared with wild type. $(D)$ Deletion of Cts B or $S$ in BMDMs reduced macrophage invasion through collagen I by $46 \%$ and $40 \%$ decrease, respectively, compared with wild type. BMDMs isolated from wild-type, $C t s B^{-1-}$, or $S^{-1-}$ mice were allowed to invade through collagen I-coated inserts. ${\left({ }^{\star \star}\right)}^{*} P<0.0001$ compared with wild type. $(E)$ Deletion of $C t s B$ or $S$ in macrophages reduced their invasion through Matrigel by $63 \%$ and $89 \%$ decrease, respectively, compared with wild type. BMDMs isolated from wild-type, Cts $B^{-/-}$, or $S^{-/-}$mice were allowed to invade through Matrigel-coated inserts. $\left(^{\star \star \star}\right) P<0.0001$ compared with wild type. Bar, $100 \mu \mathrm{m} .(F)$ Transplantation of Cts $B$ - or $S$-null BM reduces tumor vascularization in the recipient tumors. The tumor area covered by $\mathrm{CD} 1^{+}$cells was analyzed with MetaMorph software. $\left(^{\star \star}\right) P<0.01$ compared with wild type; $n=5$ mice in each group. $(C-F)$ Data are represented as mean and SEM.

BMT experiment (Fig. 4A,B). Thus, our BMT experiments collectively demonstrate that TAM-derived Cts B and $\mathrm{S}$, but not TAM-supplied Cts $\mathrm{C}$ and $\mathrm{L}$, promote the growth and invasion of cancer cells in a heterotypic manner.

To examine the mechanism by which TAM-derived Cts B and S promote tumor invasion in vivo, we performed several cell culture invasion assays. We first used a tumor cell-macrophage coculture assay, which has been employed previously to show that the BAC1 macrophage cell line significantly enhances invasion of MTLn3 breast cancer cells through a three-dimensional (3D) collagen I matrix (Goswami et al. 2005). We adapted this assay to determine if the ability of macrophages to enhance cancer cell invasion can be prevented by ablation of Cts $B$ or $S$. 
We used primary BM-derived macrophages (BMDMs) isolated from wild-type or Cts B- or S-deficient animals and the same MTLn3 cancer cells in this assay. We found that, while wild-type BMDMs cause a sevenfold increase in the invasion of cancer cells, coculture with Cts B-or $S$-null BMDMs significantly abrogated this effect $150 \%$ reduction for Cts $B^{-1-}$ BMDM $[P<0.0001]$ and $30 \%$ decrease for Cts $S^{-1-}$ BMDM $[P<0.05]$ compared with wild type) (Fig. 4C).

There are several explanations for the ability of TAMsupplied Cts B and S to enhance cancer cell invasion in a heterotypic manner in vivo, including the requirement for physical degradation of the ECM/basement membrane by macrophages to facilitate the subsequent migration of cancer cells. We found that active cathepsins are secreted from macrophages in culture, when exposed to tumor cell conditioned media $(\mathrm{CM})(\mathrm{H}-\mathrm{W}$ Wang and JA Joyce, unpubl.), indicating their availability in the extracellular milieu to perform these proposed proteolytic functions. To test whether Cts deficiency also impeded the ability of macrophages themselves to invade through ECM components, we examined invasion of Cts-null macrophages through transwell inserts coated with either collagen I or reconstituted ECM (Matrigel). Cts $B^{-1-}$ and $S^{-/-}$BMDMs were both significantly impaired in their ability to invade through either matrix (Fig. 4D,E). However, this was not due to a general defect in their migratory capabilities, as their migration through uncoated inserts was unaffected compared with wild type (data not shown). Moreover, as deletion of Cts B or $S$ in the BM did not affect the number of tumor-infiltrating immune cells (Supplemental Fig. S3B), this suggests that there are likely differences in the mechanisms involved in transendothelial migration of leukocytes from the circulation into tumors, compared with invasion through extracellular matrices. Collectively, these results indicate that macrophages lacking Cts $B$ or $S$ are defective in invading through ECM components, which appears to have profound effects on the ability of neighboring cancer cells to invade and migrate from the primary tumor mass.

We next wanted to determine whether removal of macrophage-derived Cts B or S affects angiogenesis, as this is another process that requires proteolysis. Measurement of $\mathrm{CD} 31^{+}$vessel area in the tumors from wildtype RT2 mice transplanted with wild-type or Cts $B$ - or $S$-null BM revealed that removal of either cathepsin results in a significant decrease in tumor vascularization ( $48 \%$ reduction for Cts B and $36 \%$ for Cts $S ; P<0.01$ ) (Fig. $4 \mathrm{~F})$. These data suggest that, in addition to their proinvasive roles, macrophage-derived Cts B and S have important proangiogenic functions in vivo.

\section{IL-4 induces cathepsin activity in macrophages}

Our findings that macrophages produce high levels of cathepsin activity upon infiltrating tumors and that TAM-derived cathepsin activity increases with tumor progression suggest that factors produced by the cancer cells and/or stromal cells within the tumor microenvironment are involved in triggering this activity switch.
To determine whether cancer cell-secreted proteins are capable of inducing cathepsin activity in macrophages, we designed a cell-based assay in which freshly isolated BMDCs were cultured in the presence of tumor or control cell CM, which was supplemented with colony-stimulating factor 1 (CSF-1) to induce macrophage differentiation (Fig. 5A). Cathepsin activity in the BMDMs was then analyzed by flow cytometry with the Cath-ABP. We compared the effects of CM prepared under identical conditions from four different cell lines: $\beta$ TC- 3 and $\beta$ TC-916, which were independently derived from individual RT2 tumors; $\beta \mathrm{HC}-11$ (referred to as $\beta \mathrm{HC}$ ) derived from a preneoplastic RT2 hyperplastic islet; and NIH3T3 (3T3) mouse fibroblasts as a control.

Incubation of BMDCs with $\beta$ TC-3 CM versus $\beta \mathrm{HC}$ or 3T3 CM resulted in a 2.6-fold increase in the proportion of Cath-ABP ${ }^{\text {high }}$ cells $(P<0.0001)$ (Fig. 5B,C), an induction that was similarly observed with CM from the independent $\beta$ TC-916 tumor cell line. This result suggests that, as tumors progress from premalignant lesions (as modeled by the $\beta \mathrm{HC}$ cells) to end-stage tumors (modeled by the $\beta$ TC cell lines), there is an increase in the production of secreted factors that activate cathepsins in infiltrating macrophages.

We next sought to identify these factors by comparing the cytokine profile in CM from $\beta$ TC-3 and $\beta$ TC-916 tumor cell lines with CM from $\beta \mathrm{HC}$ hyperplastic cells. Interestingly, IL-4 levels were higher in CM from either $\beta$ TC cell line compared with $\beta H C$ (Supplemental Fig. S5A). These results were confirmed by ELISA, which revealed a 29 -fold and 59.7-fold increase in the concentration of IL-4 in $\beta$ TC-3 and $\beta$ TC-916 CM, respectively, compared with $\beta \mathrm{HC}$ (Fig. 5D). In addition to IL-4, $\beta$ TC$916 \mathrm{CM}$ showed an increase in the levels of vascular endothelial growth factor (VEGF) and the chemokine CXCL16 (Supplemental Fig. S5A). To determine if any of these factors are sufficient to induce cathepsin activity up-regulation in macrophages, we incubated BMDCs with recombinant proteins and assayed cathepsin activity. Addition of two different VEGF isoforms, VEGF-120 and VEGF-164, did not increase cathepsin activity levels in BMDMs compared with the media alone control (Fig. 5E). Similarly, addition of recombinant CXCL16 had no effect. Addition of recombinant IL-4, however, resulted in a significant increase in cathepsin activity in BMDMs in a dose-dependent manner (Fig. 5E; Supplemental Fig. S5B) that was comparable with the induction observed with $\beta$ TC CM (Fig. 5C). We further verified that CSF-1 induces macrophage differentiation in BMDCs in the presence of IL-4 (Supplemental Fig. S5C), and that IL-4-treated BMDMs also exhibited other characteristic M2 TAM phenotypes, including down-regulation of M1 macrophagespecific genes and up-regulation of M2-specific genes (Supplemental Fig. S5D). Furthermore, both $\beta$ TC tumor cell lines expressed dramatically higher levels of IL-4 mRNA than either the 3T3 or $\beta$ HC cells (Supplemental Fig. S6A). Thus, among the factors we examined, IL-4 alone is capable of inducing cathepsin activity in primary macrophages in cell-based assays, and is highly expressed by cancer cells derived from pancreatic islet tumors. 
A

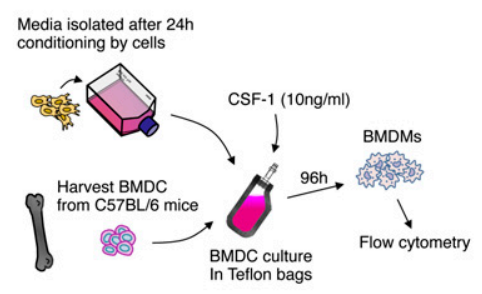

C

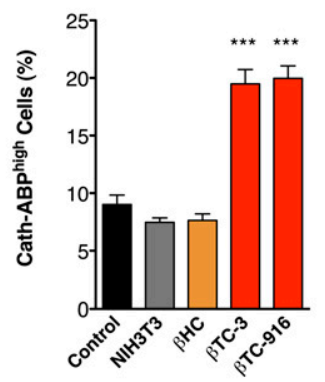

E

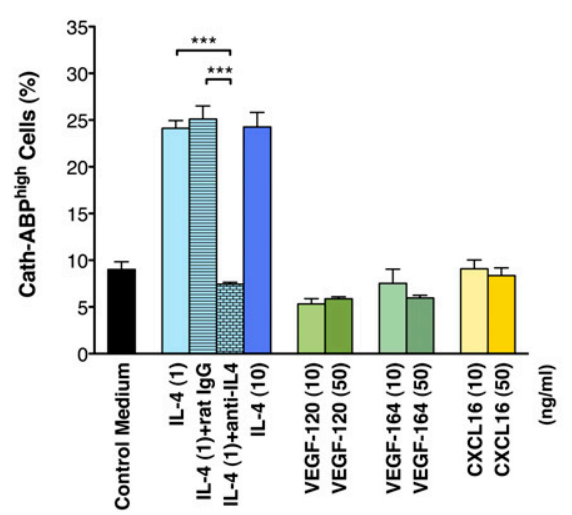

B

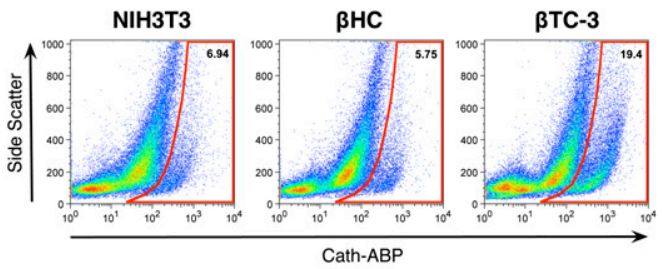

D

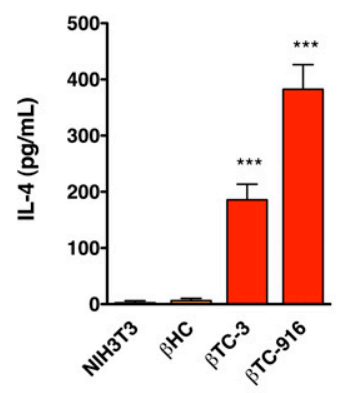

F

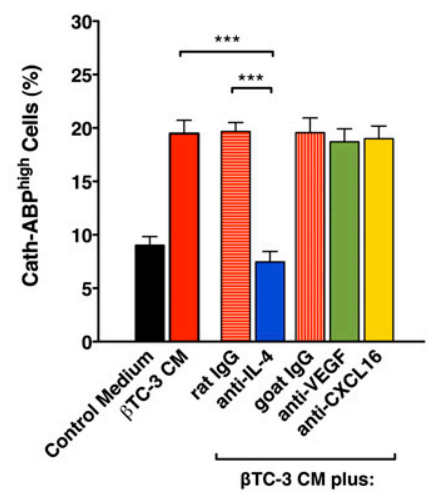

Figure 5. IL-4 induces cathepsin activity in macrophages. (A) Experimental scheme of the cell-based assay used to investigate the induction of cathepsin activity in BMDMs. $(B)$ Representative flow cytometry plots using the Cath-ABP to assess cathepsin activity in BMDMs incubated with CM prepared from three different cell lines-3T3 fibroblasts, $\beta$ HC hyperplastic cells, and $\beta$ TC-3 tumor cells-demonstrating an increased proportion of Cath-ABP ${ }^{\text {high }}$ BMDMs following incubation with $\beta$ TC-3 CM. (C) Incubation of BMDCs with $\beta$ TC-3 or $\beta$ TC-916 CM resulted in a significant induction of cathepsin activity compared with either $\beta \mathrm{HC}$ or 3T3 CM. $(D)$ The IL-4 levels in CM were measured by ELISA, revealing significantly higher levels of IL-4 in $\beta$ TC CM than either $\beta \mathrm{HC}$ or 3 T3 CM. (E) BMDCs were incubated with various recombinant proteins at indicated concentrations for $96 \mathrm{~h}$, and cathepsin activity was then determined by flow cytometry. Incubation with IL-4 significantly up-regulated cathepsin activity in BMDMs, while addition of a neutralizing antibody against IL-4, but not the isotype control IgG, abolished the effect of IL-4. Incubation with VEGF-120, VEGF-164, and CXCL16 had no effect. $(F)$ BMDCs were incubated with $\beta$ TC-3 CM plus neutralizing antibodies against IL-4, VEGF, or CXCL16 or the relevant isotype control IgG. The inductive effect of $\beta$ TC-3 CM on cathepsin activity in BMDMs was completely abrogated by addition of the IL-4 antibody, but not by antibodies to VEGF or CXCL16. (C-F) Data are represented as mean and SEM of three independent experiments performed in duplicate; $\left(^{\star \star \star}\right) P<0.0001$.

Having shown that IL-4 is sufficient to up-regulate cathepsin activity, we next asked whether cancer cellsecreted IL-4 is necessary for this induction by using function-blocking antibodies against the cytokine candidates. Addition of $\alpha$-VEGF- or $\alpha$-CXCL16-blocking antibodies to $\beta$ TC-3 CM had no effect on the levels of cathepsin activity in macrophages compared with the relevant IgG control (Fig. 5F). However, an $\alpha$-IL-4-blocking antibody significantly reduced cathepsin activity levels $(P<0.0001)$, resulting in levels comparable with the basal amount of cathepsin activity in macrophages following incubation with either control or $\beta \mathrm{HC}$ CM (Fig. 5C). Thus, IL-4 is a key factor secreted by cancer cells that induces the paracrine up-regulation of cathepsin activity in macrophages in culture.

While tumor cell lines derived from RT2 tumors clearly produce IL-4, T cells are a typical source of IL-4 in normal tissues (Martinez et al. 2008), and so we investigated the cellular sources of IL-4 in RT2 tumors. Analysis of IL-4 mRNA expression by real-time quantitative RT-PCR of 
FACS-sorted cells showed that freshly isolated RT2 tumor cells produce IL-4, as do T cells (Supplemental Fig. S6B). While T cells express IL-4 at higher levels than tumor cells, they only constitute a minor cell infiltrate in RT2 tumors (1.75\% of all cells by image analysis), compared with the tumor cells, which comprise $\sim 80 \%-$ $85 \%$ of the tumor mass.

We next asked whether the levels of IL-4 increase during tumor progression in a manner that coincides with the observed up-regulation of cathepsin activity in vivo. Real-time RT-PCR was used to evaluate IL-4 expression in RNA isolated from independent pools of normal, hyperplastic, and angiogenic islets, and tumors from RT2 mice. IL-4 expression was low in normal islets and increased by 4.5 -fold at the hyperplastic stage; however, upon the induction of angiogenic switching, the levels of IL-4 mRNA were increased by 7.7-fold in angiogenic islets and 7.9-fold in end-stage tumors (Fig. 6A). We also assessed IL-4 protein levels in RT2 tumors by ELISA and found a 6.4-fold increase compared with normal pancreas (Fig. 6B). Thus, increases in IL-4 during pancreatic tumor progression closely parallel the timing of enhanced cathepsin activation in infiltrating macrophages and strongly suggest that IL-4 is important for controlling the transition of normal macrophages into tumor-promoting macrophages.

In order to functionally validate these findings in vivo, we generated $I 14^{-/-}$RT2 mice to determine how loss of IL-4 affects cathepsin activity levels in TAMs. We found a significant $38.6 \%$ decrease in the number of Cath- $\mathrm{ABP}^{+}$ cells in $I 14^{-1-}$ RT2 mice at 13.5 wk of age (Fig. 6C,D). Critically, this is not simply a consequence of reduced macrophage infiltration in the $I 14^{-1-}$ tumors, as the numbers of TAMs did not differ from the wild-type RT2
A

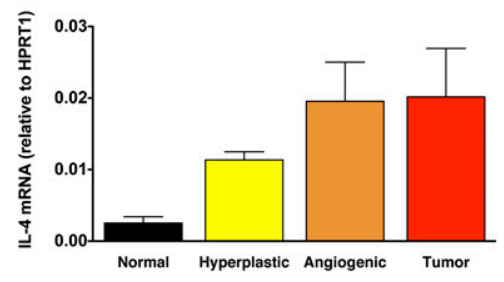

C
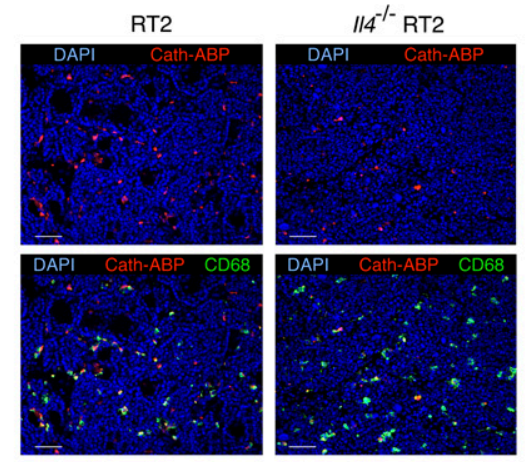

E

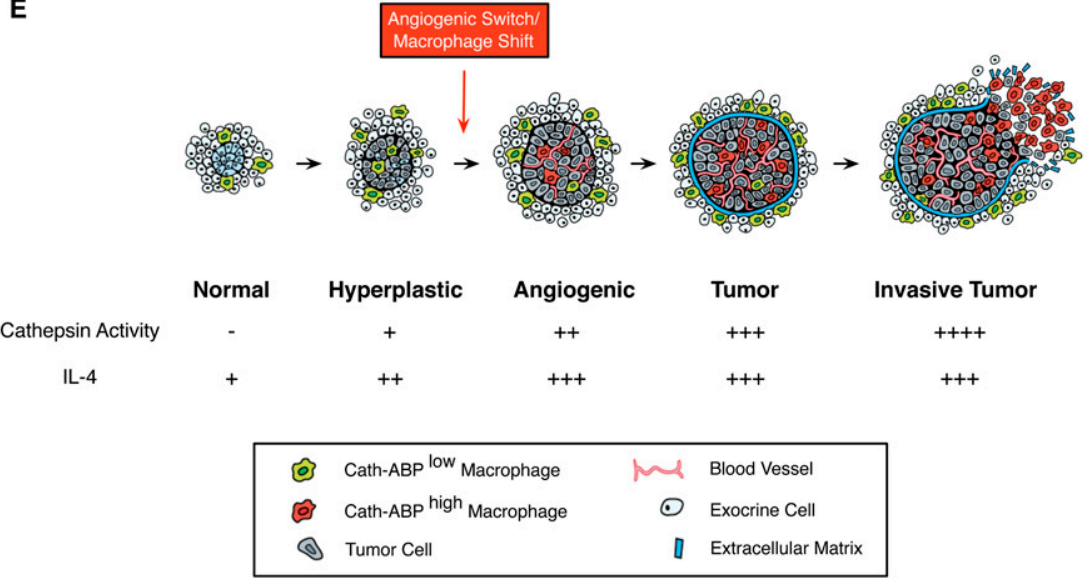

B

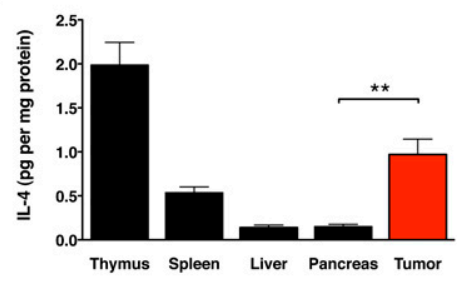

D

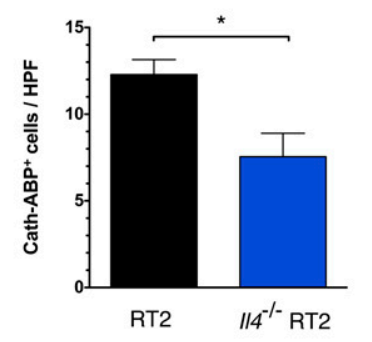

Figure 6. IL-4 levels progressively increase during tumor development and deletion of $I 14$ reduces cathepsin activity levels in vivo. (A) The levels of IL-4 expression increase during tumor progression in RT2 mice. RNA amplified from pools of lesions at the different stages $(n=$ 3-5) was analyzed using real-time quantitative RT-PCR. (B) IL-4 levels in lysates prepared from RT2 tumors or normal tissues were determined by ELISA, revealing a significant increase in IL-4 produced by tumors compared with normal pancreas; $\left(^{\star \star}\right) P<0.01$. Data are normalized to the total protein concentration. Thymus and spleen tissues, where there are abundant $\mathrm{T}$ cells, were used as positive controls for IL-4 ( $n=6-12$ mice per group). (C) Representative images showing a decrease in the number of Cath- $\mathrm{ABP}^{+}$cells within the tumors of $I 14^{-1-}$ RT2 mice as compared with $\mathrm{Il4}^{+/+}$RT2 controls. The infiltrating macrophages are costained with CD68. Bar, $50 \mu \mathrm{m}$. (D) The number of Cath- $\mathrm{ABP}^{+}$cells within the tumors of RT2 and $I 14^{-1-}$ RT2 mice was quantified by image analysis showing a $38.6 \%$ decrease; $\left(^{\star}\right) P<0.05$. Data represent mean and SEM per $40 \times$ high-power field (HPF) ( $n=6$ mice per group). (E) Model depicting the induction of cathepsin activity (as determined by Cath-ABP labeling) in infiltrating macrophages. This transition occurs concomitant with angiogenic switching in developing tumors, in response to increased expression of IL-4. Cath- $\mathrm{ABP}^{+}$macrophages are also found at the invasive edges of tumors, where they enhance cancer cell invasion by degradation of ECM proteins. 
controls (Supplemental Fig. S6C), demonstrating that IL-4 is a major factor that induces cathepsin activity in tumorinfiltrating macrophages.

\section{Discussion}

TAMs have been implicated in the pathogenesis of cancer, yet the mechanisms by which they promote tumorigenesis are incompletely understood. In this study, we identified high cathepsin protease activity as a selective property of TAMs that distinguishes them from their normal counterparts and significantly contributes to tumor growth. Moreover, the increased cathepsin activity in TAMs also enhances the invasiveness of adjacent cancer cells in a heterotypic manner. Finally, we determined that IL-4 is a major factor responsible for the induction of cathepsin activity in TAMs in vivo and in vitro.

\section{IL-4 and TAMs}

These experiments provided insight into the dynamic nature of macrophage biology over the course of tumor development. Although macrophages are clearly present in the normal and hyperplastic progenitors of pancreatic islet tumors, their phenotype changes as neoplastic lesions progress. While several cytokines have been identified that recruit macrophages to inflammatory sites and developing tumors, little is known about the tumorderived factors that selectively activate the tumorpromoting capabilities of macrophages. Here, we identified IL-4 as a key factor that regulates a critical property of TAMs; namely, the increase in cathepsin activity. This result is particularly compelling, as IL-4 also induces the M2 alternative macrophage polarization state. In contrast to the M1, or "classically activated," macrophages, which are generally cytotoxic, M2 macrophages are "alternatively activated" by a different group of cytokines, including IL-4 and IL-13, which are typically produced by $\mathrm{T}_{\mathrm{H}} 2$ cells, and promote tissue remodeling, angiogenesis, and suppression of adaptive immunity (Martinez et al. 2008). Thus, it has been proposed that TAMs may share characteristics of M2 macrophages (Mantovani et al. 2008).

Critically, we find that IL-4 expression is up-regulated concomitant with both angiogenic switching in the RT2 tumor progression pathway and the increase in cathepsin activity in TAMs. In our cell culture experiments, cancer cell-secreted IL-4 is both necessary and sufficient for activation of cathepsins in macrophages. Interestingly, in RT2 tumors, IL-4 is produced by cancer cells in addition to $\mathrm{T}$ cells, the typical source of IL-4 in physiological settings. We propose that IL-4 is a principal activator of cathepsin activity in TAMs, indicating a novel function for this cytokine in the tumor microenvironment. Interestingly, $\mathrm{CD}^{+}{ }^{+} \mathrm{T}$ cells have been shown recently to promote lung metastasis in the PyMT model, in part through IL-4-mediated effects on TAMs (DeNardo et al. 2009).

Increased levels of IL-4 expression in tumor cells have been reported for several human malignancies including breast, colon, pancreatic, ovarian, and lung cancer (Nash et al. 1998; Prokopchuk et al. 2005; Todaro et al. 2007, 2008). It has been proposed that IL-4 signaling promotes malignancy, in part through immunosuppressive effects on T cells (Olver et al. 2007), increased cancer cell proliferation (Prokopchuk et al. 2005), resistance to apoptosis (Li et al. 2008), and enhanced survival of cancer stem cells (Todaro et al. 2007). However, anti-tumor effects of IL-4 in vitro have also been reported (Olver et al. 2007). Thus, the effects of IL-4 are likely to be highly context-dependent in vivo, influenced not only by the cytokine balance in a tumor, but also by the specific adaptive and innate immune cell populations that are present. In addition, IL-4 is presumably not the only cytokine capable of inducing the TAM phenotype we describe in this study. While we found a substantial reduction in Cath- $\mathrm{ABP}^{+}$cells in $I 14^{-1-} \mathrm{RT} 2$ tumors, there were still TAMs in which cathepsins were activated. This may indicate that there are additional factors that can induce cathepsin activity in TAMs in vivo or suggest compensatory mechanisms by other cytokines, following the genetic ablation of $I 14$.

TAMs, cathepsins, and their effects on cancer cell invasion and angiogenesis

Increased macrophage infiltration is often found at the invasive front of tumors, leading to the hypothesis that TAMs directly promote tumor invasiveness (Pollard 2004). One mechanism that has been proposed for how TAMs enhance cancer cell migration is through a chemotaxis relay loop involving CSF-1, EGF, and their receptors (Wyckoff et al. 2004). In addition, TAMs can directly enhance the ability of cancer cells to invade the surrounding matrix through the production of cathepsins, as we show in the present study. Deletion of $C t s B$ or $S$ from BMDM significantly reduced tumor invasion in vivo to the same extent as we had observed previously following constitutive ablation of these genes. Moreover, restoring Cts $B$ or $S$ expression in macrophages restored tumor invasiveness to wild-type levels. Collectively, these data demonstrate that TAM-supplied Cts B and S are sufficient to enhance cancer cell growth and invasion in a heterotypic manner.

We gained further insight into the potential mechanisms underlying this result through cell culture assays where we found that $C t s$ or $S$ deletion significantly perturbed the capacity of macrophages to invade through Matrigel and collagen I and decreased their ability to promote cancer cell invasion into a 3D collagen I matrix. While Cts B and S have both been shown to cleave ECM constituent proteins such as collagens, laminin, and fibronectin in biochemical experiments (Lah et al. 1989; Buck et al. 1992; Wang et al. 2006), our experiments revealed differences in the degree of impairment. For example, deletion of $C t s S$ causes a far more pronounced defect in macrophage invasion through Matrigel compared with deletion of $C$ ts $B$, whereas ablation of $C t s B$ in macrophages results in a greater perturbation of cancer cell invasion through collagen I compared with Cts $S$ 
deletion. These results might reflect differential efficiencies with which each protease can cleave various target substrates, potentially explaining why removal of either $C t s B$ or $S$ in the BMT experiments resulted in a reduction in tumor invasiveness. In addition to ECM substrates, we previously identified the cell adhesion protein E-cadherin as a substrate of Cts B, L, and S in vitro, and found that Cts $\mathrm{B}$ and $\mathrm{S}$ generate different E-cadherin cleavage products (Gocheva et al. 2006), providing another explanation for why both proteases are required for tumor invasion, in addition to the possibility that they may have some nonredundant functions.

From these collective data, we now propose a model whereby E-cadherin is cleaved by Cts B, S, and L to initiate loosening of cell-cell contacts. Additionally, TAMs at the tumor-stromal interface produce Cts B and $S$, which contribute to degradation of ECM substrates, thus generating paths for the migration of cancer cells. Finally, macrophages and cancer cells may use a relay loop in which the proteolytic activation of secreted proteins, such as chemokines, by macrophages enhances the migration of neighboring cancer cells. Thus, the concerted action of cathepsin proteases results in the efficient cleavage of cell surface and extracellular substrates, leading to enhanced tumor growth, invasiveness, and, likely, metastasis. Indeed, removal of host-supplied Cts $B$ in the PyMT model has been shown to decrease lung colonization (Vasiljeva et al. 2006).

In addition to their proinvasive roles, we found that macrophage-derived Cts $\mathrm{B}$ and $\mathrm{S}$ also promote tumor angiogenesis. Deletion of $C t s B$ or $S$ from the BM reduced tumor vascularity to a similar degree as constitutive ablation of these genes (Gocheva et al. 2006), demonstrating that BM-supplied Cts B and S are important for promoting blood vessel formation. This could occur through both proteolysis of the BM to allow for vessel sprouting and by affecting the levels of pro- and antiangiogenic factors; interestingly, recombinant $\mathrm{Cts} S$ has been shown to degrade several anti-angiogenic factors, such as canstatin and arresten, in vitro (Wang et al. 2006). The decrease in tumor vascularization we observed in RT2 mice transplanted with $C$ ts $B$ - or $S$-null BM closely parallels the decrease in tumor growth, which could be due in part to reduced delivery of oxygen and nutrients through an impaired vasculature.

\section{Therapeutic implications for targeting stromal cells}

These findings also provide a compelling case for therapeutically targeting cells of the tumor microenvironment, particularly macrophages. Based on the present study, targeting IL-4, an upstream regulator of the TAM state in our model, is one possibility. Several IL-4 antagonists have been developed for clinical evaluation in inflammatory conditions, such as asthma (Steinke 2004), where, similar to tumors, chronic inflammatory infiltrates are important contributors to the pathology of the disease. However, anti-tumor effects of IL-4 in vitro have also been reported (Topp et al. 1995; Olver et al. 2007), which led to the development of clinical trials testing recombinant IL-4 as an anti-cancer therapy in renal cell carcinoma, non-small-cell lung cancer, and malignant melanoma that were discontinued due to lack of efficacy (Whitehead et al. 1998, 2002).

Alternatively, one can envision targeting the conscripted stromal cells themselves or the factors they produce-in this case, cathepsins. For example, we previously used the JPM-OEt pan-cathepsin inhibitor in stage-specific trials in the RT2 model, which resulted in decreased angiogenic switching and tumor growth and invasion (Joyce et al. 2004). Given that deletion of either Cts B or $S$ from TAMs similarly reduces tumor growth and invasiveness, a significant proportion of the therapeutic efficacy of JPM-OEt can likely be attributed to inhibition of TAMderived cathepsins. Thus, one could consider specifically "delivering" such inhibitors to TAMs, or, as there is minimal toxicity with many of the cathepsin inhibitors used to date (Palermo and Joyce 2008), they could be administered systemically. In conclusion, the identification of factors that are differentially produced by conscripted cells in the tumor microenvironment provides a strategy to selectively target these cells in combination with targeting the cancer cells, an approach that could have significant therapeutic potential.

\section{Materials and methods}

\section{Materials and mice}

The generation of RT2 (Hanahan 1985), Cts $B^{-1-}$ (Halangk et al. 2000), Cts $C^{-1-}$ (Pham and Ley 1999), Cts $L^{-/-}$(Roth et al. 2000), and $C t s S^{-1-}$ (Shi et al. 1999) mice, and each of the four constitutive Cts-null RT2 lines (Gocheva et al. 2006) have been reported previously. $\beta$-Actin GFP transgenic mice (Okabe et al. 1997) and I14 ${ }^{-/-}$mice (Kuhn et al. 1991), both in the C57BL/6 background, were purchased from Jackson Laboratories. PyMT mice were obtained from K. Podsypanina and $\mathrm{H}$. Varmus and were described previously (Guy et al. 1992; Lin et al. 2003). Wildtype mice were either age-matched littermates of RT2 mice or C57BL/6 mice purchased from Charles River Laboratories. The $\beta$ TC-3 and $\beta$ TC-916 cell lines were derived independently from individual RT2 tumors, and the $\beta \mathrm{HC}-11$ cell line was derived from a preneoplastic RT2 hyperplastic islet (Efrat et al. 1988). The $\beta$ TC- 3 and $\beta$ HC-11 lines were provided by D. Hanahan. The MTLn3 line (Goswami et al. 2005) was provided by J. Condeelis, and $3 \mathrm{~T} 3$ cells were purchased from American Type Culture Collection. The Cy3B-Cathepsin-ABP was synthesized as described previously (Greenbaum et al. 2002), with the modification that $\mathrm{Cy} 3 \mathrm{~B}$ was used as the fluorophore.

\section{Immunohistochemistry}

For invasion grading, hematoxylin and eosin (H\&E) staining was performed, and the lesions were graded as described previously (Lopez and Hanahan 2002), following a double-blind protocol, and independently assessed by two investigators. For immunofluorescence, $10-\mu \mathrm{m}$-thick frozen sections were fixed in acetone, preincubated with $1 \times$ PNB-blocking buffer, and incubated with the primary antibody of interest overnight at $4^{\circ} \mathrm{C}$. The following anti-mouse antibodies were used: rat CD45 (1:100), rat CD31 (1:200), rat CD11b (1:200), rat CD3 (1:100), rat B220 (1:100), and rat Gr1 (1:250) from BD Pharmingen; goat Cts B (1:1000), goat anti-human Cts S (1:300), goat Cts L (1:500), and Cts C (1:750) 
from R\&D Systems; rat CD68 (1:1000), rat F4/80 (1:1000), and rat $7 / 4$ (1:200) from Serotec; rat PDGFR $\beta$ (1:100) and EpCAM (1:250) from eBioscience; rabbit NG2 (1:200; Chemicon); rabbit antiGFP (1:200; Invitrogen); mouse SMA (1:400; Sigma); rabbit Iba1 (1:1000; WAKO Chemicals). The corresponding secondary antibodies were used at a 1:500 dilution and incubated for $1 \mathrm{~h}$ at room temperature. Species-matched immunoglobulins were used as negative controls. Slides were mounted in ProLong Gold Mounting Medium containing DAPI (Invitrogen), and the tissue sections were visualized under a Carl Zeiss Axioimager Z1 microscope equipped with an Apotome. The analysis of immunofluorescence staining and colocalization studies were performed using TissueQuest analysis software (TissueGnostics) as described previously (Steiner et al. 2000). This method has been used previously to quantitate both numbers of cells and provide phenotypic characterization of macrophages using CD68 and Ibal as markers (Kozakowski et al. 2009; Liesz et al. 2009). For the angiogenesis analysis, the percentage of $\mathrm{CD} 31^{+}$area over the total tumor area was analyzed using MetaMorph (Molecular Devices). The numbers of tumors and mice analyzed are specified in the figure legends.

\section{Flow cytometry and sorting}

Tumors from RT2 mice were isolated and processed for FACS analysis or sorting as described previously (Song et al. 2005). PyMT tumors and other tissues were processed as described in the Supplemental Material.

\section{$B M T$}

BM was harvested from wild-type or Cts-null $\beta$-actin-GFP mice by flushing the femurs and tibias with X-VIVO 20 medium (Cambrex). The flushed cells were resuspended in PBS, and $1 \times$ $10^{6}$ nucleated cells were injected through the tail veins of 4-wkold lethally irradiated (950 rad) wild-type or Cts-deficient RT2 animals. After $4 \mathrm{wk}$, recipient mice were bled from the orbital sinus to evaluate BMT efficiency by determining the percentage of $\mathrm{GFP}^{+}$cells using flow cytometry. Mice were subsequently aged to $13.5 \mathrm{wk}$ for calculation of tumor volume and analysis of the tumor phenotype.

\section{Macrophage invasion assay}

To derive primary macrophages, BM was harvested from wildtype or Cts-null mice by flushing femurs and tibias with DMEM media. Cells were grown with DMEM media containing 10\% FBS and $10 \mathrm{ng} / \mathrm{mL}$ recombinant mouse CSF-1 (R\&D Systems) for $5 \mathrm{~d}$. Adherent macrophages were stained using Cell Tracker Red CMTPX (Invitrogen) according to the manufacturer's instructions and allowed to migrate through Matrigel-coated inserts (BD BioCoat) for $8 \mathrm{~h}$. For the collagen I invasion assay, each insert was coated with $50 \mu \mathrm{L}$ of a 1:4 collagen I:70\% ethanol mixture overnight at room temperature. Cells were then plated and allowed to migrate for $8 \mathrm{~h}$. Invading cells were visualized using a Carl Zeiss Axiovert 200M microscope, and cells were counted using Volocity imaging software. Data were collected from at least three independent experiments performed in triplicate.

\section{$3 D$ invasion assay}

Primary macrophages were derived as above. Invasion of cancer cells through a 3D collagen I matrix was performed as described previously (Goswami et al. 2005). Briefly, 80,000 MTLn3 cells were plated alone or in the presence of 200,000 BMDMs in 35-mm MatTek dishes. A collagen I matrix (BD Pharmingen) was added over cells $24 \mathrm{~h}$ after plating. Cells were allowed to migrate through the collagen I matrix for $24 \mathrm{~h}$, and the number of cancer cells migrating $\geq 15 \mu \mathrm{m}$ was quantified using confocal microscopy. Data were collected from at least three independent experiments performed in triplicate.

\section{Assessment of cathepsin activity in CM-treated macrophages}

To obtain CM, cells were seeded at $2 \times 10^{6}$ to $6 \times 10^{6}$ cells per $75 \mathrm{~cm}^{2}$ and cultured until $80 \%$ confluent. Thereafter, the media were replaced with DMEM supplemented with $10 \%$ FBS, and the supernatants were collected after $24 \mathrm{~h}$ of additional incubation. BM was harvested from wild-type C57BL/6 mice aged 8 to $12 \mathrm{wk}$. Aliquots of $5 \times 10^{6}$ BMDCs were cultured in Teflon (FEP) bags (American Fluoroseal) containing $5 \mathrm{~mL}$ of DMEM or DMEM plus CM at 1:1 ratio, supplemented with $10 \%$ FBS. CSF-1 $(10 \mathrm{ng} / \mathrm{mL})$ was added to induce macrophage differentiation. The media were replaced at $48 \mathrm{~h}$. After $96 \mathrm{~h}$ of incubation, BMDMs were collected, and cathepsin activity was assessed by flow cytometry.

Additional experimental procedures can be found in the Supplemental Material.

\section{Acknowledgments}

We thank Keni Simpson and Xiaoping Chen for excellent technical assistance, and are grateful for assistance from the following MSKCC core facilities: Organic Synthesis, Flow Cytometry, Molecular Cytology, and Genomics, including Drs. Ouathek Ouerfelli, Guangli Yang, Agnes Viale, Jennifer Wilshire, Tao Tong, and Yevgeniy Romin. We thank Drs. Thomas Reinheckel, Christoph Peters, Hal Chapman, and Christine Pham for providing the original breeding pairs of the individual Cts knockout lines; Dr. Doug Hanahan for providing the $\beta \mathrm{HC}$ and $\beta$ TC-3 cell lines; and Dr. John Condeelis and Yarong Wang for advice with the 3D invasion assay and for providing the MTLn3 cell line. We are grateful to Drs. Robert Benezra, Harold Varmus, Carmela Palermo, and Alberto Schuhmacher for insightful feedback on the manuscript. This research was supported by the following: National Cancer Institute (NIH R01-CA125162), Geoffrey Beene Foundation, Sidney Kimmel Foundation for Cancer Research, Rita Allen Foundation, Emerald Foundation, and the Society of MSKCC (J.A.J.); Frank L. Horsfall Fellowship and Geoffrey Beene Fellowship (V.G.); Taiwan Merit Scholarship (H.-W.W.); American Cancer Society Post-doctoral Fellowship (B.B.G.); Howard Hughes Medical Institute Medical Research Training Program (A.L.G.); Grayer Fellowship (K.E.H.); the graduate training programs of Weill-Cornell Medical School (V.G. and H.-W.W.); the Tri-Institutional MD-PhD program (T.S.); and the Gerstner Sloan-Kettering Graduate School (K.E.H.).

\section{References}

Buck MR, Karustis DG, Day NA, Honn KV, Sloane BF. 1992. Degradation of extracellular-matrix proteins by human cathepsin B from normal and tumour tissues. Biochem I 282: 273-278.

DeNardo DG, Barreto JB, Andreu P, Vasquez L, Tawfik D, Kolhatkar N, Coussens LM. 2009. $\mathrm{CD}^{+} \mathrm{T}$ cells regulate pulmonary metastasis of mammary carcinomas by enhancing protumor properties of macrophages. Cancer Cell 16: 91102.

Efrat S, Linde S, Kofod H, Spector D, Delannoy M, Grant S, Hanahan D, Baekkeskov S. 1988. $\beta$-Cell lines derived from transgenic mice expressing a hybrid insulin gene-oncogene. Proc Natl Acad Sci 85: 9037-9041. 
Gocheva V, Zeng W, Ke D, Klimstra D, Reinheckel T, Peters C, Hanahan D, Joyce JA. 2006. Distinct roles for cysteine cathepsin genes in multistage tumorigenesis. Genes \& Dev 20: 543-556.

Goswami S, Sahai E, Wyckoff JB, Cammer M, Cox D, Pixley FJ, Stanley ER, Segall JE, Condeelis JS. 2005. Macrophages promote the invasion of breast carcinoma cells via a colonystimulating factor-1/epidermal growth factor paracrine loop. Cancer Res 65: 5278-5283.

Greenbaum D, Baruch A, Hayrapetian L, Darula Z, Burlingame A, Medzihradszky KF, Bogyo M. 2002. Chemical approaches for functionally probing the proteome. Mol Cell Proteomics 1: $60-68$.

Guy CT, Cardiff RD, Muller WJ. 1992. Induction of mammary tumors by expression of polyomavirus middle T oncogene: A transgenic mouse model for metastatic disease. Mol Cell Biol 12: 954-961.

Halangk W, Lerch MM, Brandt-Nedelev B, Roth W, Ruthenbuerger M, Reinheckel T, Domschke W, Lippert H, Peters C, Deussing J. 2000. Role of cathepsin B in intracellular trypsinogen activation and the onset of acute pancreatitis. J Clin Invest 106: 773-781.

Hanahan D. 1985. Heritable formation of pancreatic $\beta$-cell tumours in transgenic mice expressing recombinant insulin/ simian virus 40 oncogenes. Nature 315: 115-122.

Hazen LG, Bleeker FE, Lauritzen B, Bahns S, Song J, Jonker A, Van Driel BE, Lyon H, Hansen U, Kohler A, et al. 2000. Comparative localization of cathepsin B protein and activity in colorectal cancer. J Histochem Cytochem 48: 1421-1430.

Iacobuzio-Donahue CA, Shuja S, Cai J, Peng P, Murnane MJ. 1997. Elevations in cathepsin B protein content and enzyme activity occur independently of glycosylation during colorectal tumor progression. J Biol Chem 272: 29190-29199.

Joyce JA, Pollard JW. 2009. Microenvironmental regulation of metastasis. Nat Rev Cancer 9: 239-252.

Joyce JA, Baruch A, Chehade K, Meyer-Morse N, Giraudo E, Tsai FY, Greenbaum DC, Hager JH, Bogyo M, Hanahan D. 2004. Cathepsin cysteine proteases are effectors of invasive growth and angiogenesis during multistage tumorigenesis. Cancer Cell 5: 443-453

Kozakowski N, Bohmig GA, Exner M, Soleiman A, Huttary N, Nagy-Bojarszky K, Ecker RC, Kikic Z, Regele H. 2009. Monocytes/macrophages in kidney allograft intimal arteritis: No association with markers of humoral rejection or with inferior outcome. Nephrol Dial Transplant 24: 1979-1986.

Kuhn R, Rajewsky K, Muller W. 1991. Generation and analysis of interleukin-4 deficient mice. Science 254: 707-710.

Lah TT, Buck MR, Honn KV, Crissman JD, Rao NC, Liotta LA, Sloane BF. 1989. Degradation of laminin by human tumor cathepsin B. Clin Exp Metastasis 7: 461-468.

Li Z, Jiang J, Wang Z, Zhang J, Xiao M, Wang C, Lu Y, Qin Z. 2008. Endogenous interleukin-4 promotes tumor development by increasing tumor cell resistance to apoptosis. Cancer Res 68: 8687-8694.

Liesz A, Suri-Payer E, Veltkamp C, Doerr H, Sommer C, Rivest S, Giese T, Veltkamp R. 2009. Regulatory T cells are key cerebroprotective immunomodulators in acute experimental stroke. Nat Med 15: 192-199.

Lin EY, Jones JG, Li P, Zhu L, Whitney KD, Muller WJ, Pollard JW. 2003. Progression to malignancy in the polyoma middle T oncoprotein mouse breast cancer model provides a reliable model for human diseases. Am J Pathol 163: 2113-2126.

Lindahl C, Simonsson M, Bergh A, Thysell E, Antti H, Sund M, Wikstrom P. 2009. Increased levels of macrophage-secreted cathepsin $\mathrm{S}$ during prostate cancer progression in TRAMP mice and patients. Cancer Genomics Proteomics 6: 149-159.
Lopez T, Hanahan D. 2002. Elevated levels of IGF-1 receptor convey invasive and metastatic capability in a mouse model of pancreatic islet tumorigenesis. Cancer Cell 1: 339-353.

Mantovani A, Allavena P, Sica A, Balkwill F. 2008. Cancerrelated inflammation. Nature 454: 436-444.

Martinez FO, Helming L, Gordon S. 2008. Alternative activation of macrophages: An immunologic functional perspective. Annu Rev Immunol 27: 451-483.

Mohamed MM, Sloane BF. 2006. Cysteine cathepsins: Multifunctional enzymes in cancer. Nat Rev Cancer 6: 764-775.

Murdoch C, Muthana M, Coffelt SB, Lewis CE. 2008. The role of myeloid cells in the promotion of tumour angiogenesis. Nat Rev Cancer 8: 618-631.

Nash MA, Lenzi R, Edwards CL, Kavanagh JJ, Kudelka AP, Verschraegen CF, Platsoucas CD, Freedman RS. 1998. Differential expression of cytokine transcripts in human epithelial ovarian carcinoma by solid tumour specimens, peritoneal exudate cells containing tumour, tumour-infiltrating lymphocyte (TIL)-derived T cell lines and established tumour cell lines. Clin Exp Immunol 112: 172-180.

Okabe M, Ikawa M, Kominami K, Nakanishi T, Nishimune Y. 1997. 'Green mice' as a source of ubiquitous green cells. FEBS Lett 407: 313-319.

Olver S, Apte S, Baz A, Kienzle N. 2007. The duplicitous effects of interleukin 4 on tumour immunity: How can the same cytokine improve or impair control of tumour growth? Tissue Antigens 69: 293-298.

Palermo C, Joyce JA. 2008. Cysteine cathepsin proteases as pharmacological targets in cancer. Trends Pharmacol Sci 29: 22-28.

Pham CT, Ley TJ. 1999. Dipeptidyl peptidase I is required for the processing and activation of granzymes A and B in vivo. Proc Natl Acad Sci 96: 8627-8632.

Pollard JW. 2004. Tumour-educated macrophages promote tumour progression and metastasis. Nat Rev Cancer 4: 71-78.

Prokopchuk O, Liu Y, Henne-Bruns D, Kornmann M. 2005. Interleukin-4 enhances proliferation of human pancreatic cancer cells: Evidence for autocrine and paracrine actions. Br J Cancer 92: 921-928.

Roth W, Deussing J, Botchkarev VA, Pauly-Evers M, Saftig P, Hafner A, Schmidt P, Schmahl W, Scherer J, Anton-Lamprecht I, et al. 2000. Cathepsin L deficiency as molecular defect of furless: Hyperproliferation of keratinocytes and pertubation of hair follicle cycling. FASEB J 14: 2075-2086.

Shi GP, Villadangos JA, Dranoff G, Small C, Gu L, Haley KJ, Riese R, Ploegh HL, Chapman HA. 1999. Cathepsin S required for normal MHC class II peptide loading and germinal center development. Immunity 10: 197-206.

Song S, Ewald AJ, Stallcup W, Werb Z, Bergers G. 2005. PDGFR $\beta^{+}$perivascular progenitor cells in tumours regulate pericyte differentiation and vascular survival. Nat Cell Biol 7: 870-879.

Steiner GE, Ecker RC, Kramer G, Stockenhuber F, Marberger MJ. 2000. Automated data acquisition by confocal laser scanning microscopy and image analysis of triple stained immunofluorescent leukocytes in tissue. I Immunol Methods 237: 39-50.

Steinke JW. 2004. Anti-interleukin-4 therapy. Immunol Allergy Clin North Am 24: 599-614.

Sullivan S, Tosetto M, Kevans D, Coss A, Wang L, O'Donoghue D, Hyland J, Sheahan K, Mulcahy H, O'Sullivan J. 2009. Localization of nuclear cathepsin $\mathrm{L}$ and its association with disease progression and poor outcome in colorectal cancer. Int J Cancer 125: 54-61.

Tlsty TD, Coussens LM. 2006. Tumor stroma and regulation of cancer development. Annu Rev Pathol 1: 119-150. 
Todaro M, Alea MP, Di Stefano AB, Cammareri P, Vermeulen L, Iovino F, Tripodo C, Russo A, Gulotta G, Medema JP, et al. 2007. Colon cancer stem cells dictate tumor growth and resist cell death by production of interleukin-4. Cell Stem Cell 1: 389-402.

Todaro M, Lombardo Y, Francipane MG, Alea MP, Cammareri P, Iovino F, Di Stefano AB, Di Bernardo C, Agrusa A, Condorelli $\mathrm{G}$, et al. 2008. Apoptosis resistance in epithelial tumors is mediated by tumor-cell-derived interleukin-4. Cell Death Differ 15: 762-772.

Topp MS, Papadimitriou CA, Eitelbach F, Koenigsmann M, Oelmann E, Koehler B, Oberberg D, Reufi B, Stein H, Thiel $\mathrm{E}$, et al. 1995. Recombinant human interleukin 4 has antiproliferative activity on human tumor cell lines derived from epithelial and nonepithelial histologies. Cancer Res 55: 2173-2176.

Vasiljeva O, Papazoglou A, Kruger A, Brodoefel H, Korovin M, Deussing J, Augustin N, Nielsen BS, Almholt K, Bogyo M, et al. 2006. Tumor cell-derived and macrophage-derived cathepsin B promotes progression and lung metastasis of mammary cancer. Cancer Res 66: 5242-5250.

Vasiljeva O, Reinheckel T, Peters C, Turk D, Turk V, Turk B. 2007. Emerging roles of cysteine cathepsins in disease and their potential as drug targets. Curr Pharm Des 13: 387-403.

Wang B, Sun J, Kitamoto S, Yang M, Grubb A, Chapman HA, Kalluri R, Shi GP. 2006. Cathepsin S controls angiogenesis and tumor growth via matrix-derived angiogenic factors. I Biol Chem 281: 6020-6029.

Whitehead RP, Unger JM, Goodwin JW, Walker MJ, Thompson JA, Flaherty LE, Sondak VK. 1998. Phase II trial of recombinant human interleukin-4 in patients with disseminated malignant melanoma: A Southwest Oncology Group study. I Immunother 21: 440-446.

Whitehead RP, Lew D, Flanigan RC, Weiss GR, Roy V, Glode ML, Dakhil SR, Crawford ED. 2002. Phase II trial of recombinant human interleukin-4 in patients with advanced renal cell carcinoma: A Southwest Oncology Group study. I Immunother 25: 352-358.

Wyckoff J, Wang W, Lin EY, Wang Y, Pixley F, Stanley ER, Graf T, Pollard JW, Segall J, Condeelis J. 2004. A paracrine loop between tumor cells and macrophages is required for tumor cell migration in mammary tumors. Cancer Res 64: 70227029. 


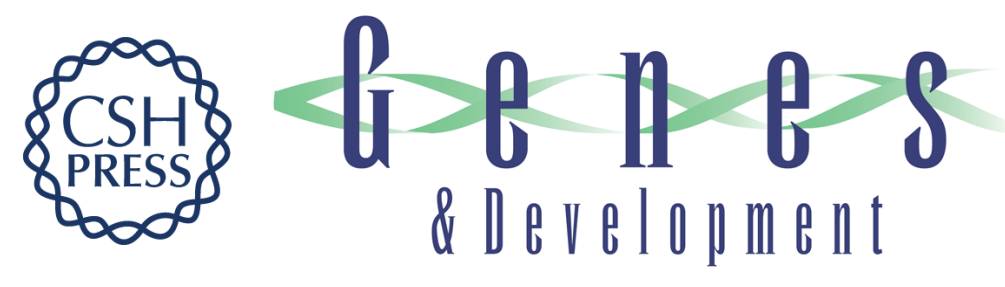

\section{IL-4 induces cathepsin protease activity in tumor-associated macrophages to promote cancer growth and invasion}

Vasilena Gocheva, Hao-Wei Wang, Bedrick B. Gadea, et al.

Genes Dev. 2010, 24: originally published online January 15, 2010

Access the most recent version at doi:10.1101/gad.1874010

\section{Supplemental http://genesdev.cshlp.org/content/suppl/2009/12/30/gad.1874010.DC1 Material}

References This article cites 48 articles, 15 of which can be accessed free at: http://genesdev.cshlp.org/content/24/3/241.full.html\#ref-list-1

\section{License}

Email Alerting

Receive free email alerts when new articles cite this article - sign up in the box at the top Service

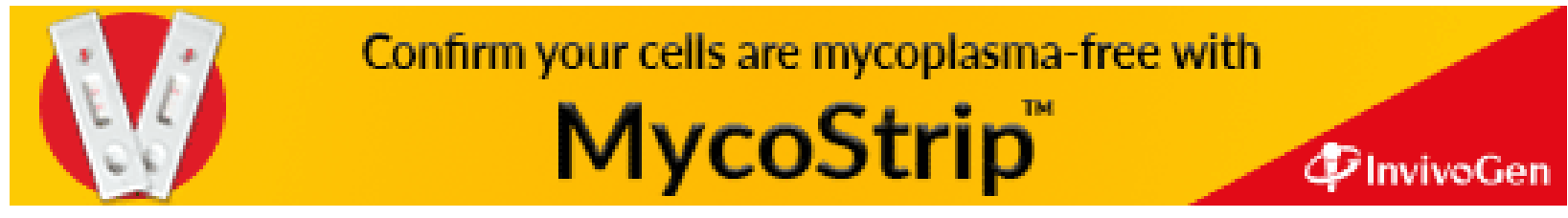

